\title{
Blocking Effect of Natural Alkaloids on COVID-19 Pentameric Ion Channel: An in silico Perspective
}

\author{
Mohammad Bayati ${ }^{1}$ (D), Samad Nejad Ebrahimi 1,*(D) \\ 1 Department of Phytochemistry, Medicinal Plants and Drugs Research Institute, Shahid Beheshti University, Tehran, Iran \\ * Correspondence: s_ebrahimi@sbu.ac.ir (S.N.E.);
}

Scopus Author ID 9338406700

Received: 3.08.2021; Revised: 10.09.2021; Accepted: 14.09.2021; Published: 17.10.2021

\begin{abstract}
Numerous deaths worldwide have been caused by the coronavirus pandemic and are currently progressing with successive mutations and a lack of appropriate and definitive treatment. One of the drug targets to control the replication of the virus and treat this disease is to block the ion channel of the virus. This will lead to its death by disturbing the internal balance of the virus. Natural compounds such as alkaloids are usually known as effective compounds due to their medicinal characteristics and easy access to their sources. To this end, more than 3,200 natural alkaloid structures interacted with pentameric ion channels. Alkaloid compounds established significant and stable interactions with the channel. More clearly and in more detail, six alkaloid compounds with the best pharmacokinetics and binding affinity of less than $-10.52 \mathrm{kcal} / \mathrm{mol}$ were selected as hit and suitable compounds for virus control. The compound of psammaplysin U (NA-1) with a binding affinity of $-13.52 \mathrm{kcal} / \mathrm{mol}$ and binding free energy of $-82.21 \mathrm{kcal} / \mathrm{mol}$ established hydrogen interactions with the amino acid of $\mathrm{Val} 25$ in the B chain of the ion channel, which placed the compound at the top of the selected compounds. The molecular dynamics simulation of the ligand-protein complex in the 100 ps trajectory showed that the principal interactions were hydrogen and halogen bonding with the amino acids of Val 25 and Thr 30 in the B chain and A chain, respectively, which could be a suitable inhibitor to combat the COVID19.
\end{abstract}

Keywords: ADMET; alkaloids; COVID-19; coronavirus; ion channel; molecular docking; molecular dynamics; SARS-CoV-2.

(C) 2021 by the authors. This article is an open-access article distributed under the terms and conditions of the Creative Commons Attribution (CC BY) license (https://creativecommons.org/licenses/by/4.0/).

\section{Introduction}

The emergence of a new coronavirus termed severe acute respiratory syndrome coronavirus 2 (SARS-CoV-2) at the end of 2019 led to an epidemic in several Chinese provinces, including Wuhan. The World Health Organization (WHO) declared a state of crisis and gave it the official name of COVID-19 after the death toll exceeded 1,000. The latest cases and death rates in the world as of September 2021 were more than 219 and 4.55 million, respectively. The most common symptoms of this disease are fever, myalgia, dry cough, chest pain, and fatigue. Still, in some cases, dizziness, nausea, diarrhea, sore throat, rash, and paleness of the fingers and toes are observed [1], and even in rare cases, patients lose their taste and smell sense [2].

The various similarities of the virus with SARS and MERS caused epidemics in multiple nations worldwide in 2002 and 2012, respectively, placing it within the Coronaviridae family and Coronavirinae subfamily [3,4]. Cryo-electron microscopic studies have revealed that the corona is a spherical virus with approximately $125 \mathrm{~nm}$ diameter [5]. Coronaviruses 
contain envelope and single-stranded RNA. They are divided into four different groups: alpha, beta, gamma and, delta. The COVID-19 is considered the Betacoronavirus [6]. The virus has four main structures: nucleocapsid, membrane, spike, envelope, and several non-structural proteins [7]. In this way, each protein plays a vital role in the virus's life and reproduction.

The E protein with an 8-12 $\mathrm{kDa}$ weight has an ion channel activity with two different terminals, including an $\mathrm{N}$-terminal ectodomain and a $\mathrm{C}$-terminal endodomain, as shown in Figure 1 [8-10]. Protein $\mathrm{E}$ is surrounded by protein $\mathrm{M}$ and consists of 75 to 109 amino acids and an $\alpha$-helical transmembrane. The role and function of the E protein (viroporin ion channel) have not been clarified completely, but it is expected to regulate ionic balance inside and outside the cell, which is very critical in the life and pathogenesis of the virus. However, others have recommended that E protein may promote viral release by modifying the host secretory pathway [11]. It has been reported that the protein has a pathogenic function in the SARS and MERS viruses. Stated that mice infected with the coronavirus lacking the E protein reduced mortality [12]. Viruses such as hepatitis C, HIV-1, and influenza A that cause human disease are RNA viruses that express viroporin [13].

Nowadays, the expansion of complementary therapies, natural medication are finding their place. Fallah et al. (2021) [14] stated that natural compounds in the essential oil and extract belonging to Panax ginseng and Sambucus nigra demonstrate a potential affinity against the SARS-CoV-2 spike RBD. Alkaloids with bioactive characteristics are notable compounds in pharmaceutical industries [15]. Alkaloid compounds such as atropine, capsaicin, colchicine, and trigonelline had antiviral impacts on RNA and DNA of HSV-1 and PI-3 viruses, respectively [16]. Alkaloids are known for representing a broad spectrum of biological characteristics, such as being $\mathrm{Ca}^{+2}$ channel blockers and enzyme inhibitors [17], being antimalarial [18], cytotoxic [19], anti-infective, and antimicrobial [20]. Previous research reported that alkaloids such as isoboldine have a significant inhibitory effect on SARS-COV2 protease and showed excellent oral absorption [21]. Polycyclic guanidine alkaloids isolated from Monanchora $\mathrm{n}$. sp. were examined for antiviral potentials against five COVID-19 proteins (nsp10, main protease, membrane glycoprotein, spike glycoproteins, and nucleocapsid phosphoprotein), compounds of Crambescidin 786 and Crambescidin 826 exhibited promising in silico ADMET, and the best binding modes and free energies results [22]. Another study reported that quinoline and quinazoline Alkaloids such as norquinadoline A, deoxynortryptoquivaline, and deoxytryptoquivaline inhibited three protein targets of SARSCOV-2 and showed excellent pharmacokinetic and safety profiles [23].
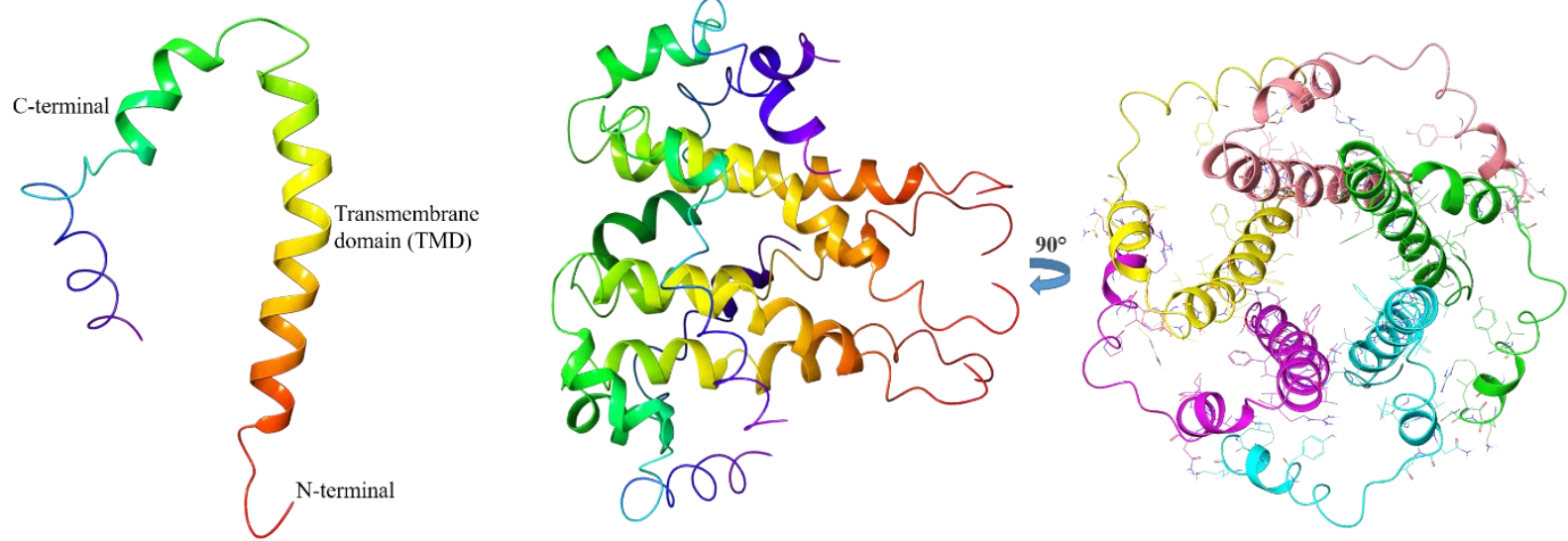

Figure 1. Pentameric ion channel of SARS CoV-2 (PDB: 5X29). 
Particular medication or vaccine production process requires at least ten years from bench research to approve [24,25]. At the moment, performing computational design and drug discovery can considerably reduce both the cost and the time required for medication development [26]. In addition, the successive mutations of the COVID-19 and the lack of definitive treatment, this study aims to find a suitable and potent inhibitor using molecular docking and dynamics simulation to prevent replication of the virus. The interaction of the hit compounds with the E protein will be examined; it shows how the receptor is blocked and disturb the internal balance of the virus. On the other hand, it will show the ADMET properties of hit poses.

\section{Materials and Methods}

\subsection{Preparation of alkaloid structures.}

More than 3200 natural alkaloid compounds were obtained from Database for Rapid Dereplication of Known Natural Products (DEREP-NP) openly obtainable at (https://github.com/clzani/DEREP-NP) then prepared through LigPrep software of maestro Schrödinger 2015. To create the required 3D structures, the ionization state and compounds' chirality of the compounds remained intact, the present salts were removed, and only one structure holding the minimum energy was generated for each alkaloid compound.

\subsection{Preparation of receptor.}

The NMR structure of the pentameric ion channel of the coronavirus was obtained from the protein data bank (PDB ID: 5X29, https://www.rcsb.org). Optimization of the receptor was performed using the Protein preparation program of the maestro Schrödinger package 10.5 (2015). In the preparation process, hydrogen atoms were added to the amino acids, zero-order metal bonds and disulfide bonds were formed in the protein's chains. Missing loops and side chains were created by Prime software. Selenomethionine was converted to methionine, and water molecules were removed beyond $3 \AA$ from the het groups. The PROPKA was employed to predict the $\mathrm{pKa}$ of ionizable groups of the receptor at $\mathrm{pH} 7.00$. Ultimately, the OPLS3 force field optimized and minimized the pentameric ion channel of SARS-CoV-2.

\subsection{Active binding site identification.}

Active site prediction is required for molecular docking in a suitable position. According to Abreu et al. (2020) [27], establishing the hydrogen bonds with amino acid residues of Phe 26 and Ala 22 blocks the channel. The Sitemapping application was used for the prediction and validation of the active site (Maestro 10.5). For this purpose, the site map with a site score of more than one was selected as an active pocket site among five predicted sites. According to the mentioned information, the grid box was made in midpoints (X: -0.35 , Y: -0.01, Z: -0.22) and with suitable dimensions (X, Y, Z: $20 \AA$ A) by Receptor Grid Generation Schrödinger package.

\subsection{Molecular docking study.}

The glide of maestro Schrödinger was used to dock alkaloid compounds and investigate their interaction with amino acid residues in the active binding site of the E protein (5X29). A partial charge of 0.15 , as well as a scaling factor of 0.8 , was used to soften the potential for 
nonpolar parts of the compounds. In the docking process, entire compounds were considered flexible and rotated freely (nitrogen inversions and ring conformations). First of all, a large number of the ligands were docked with high throughput virtual screening (HTVS) precision for fast virtual screening and identifying effective alkaloids, then $30 \%$ of the best poses with the highest docking scores were examined for XP (extra precision) docking. Finally, more than 200 hit compounds were selected for further analysis. Molecular docking results were expressed in $\mathrm{kcal} / \mathrm{mol}$.

\subsection{Free binding energy.}

Prime molecular mechanics generalized Born surface area (MM-GBSA) module was applied to calculate the sum of entire intermolecular interactions in the protein-ligand complex. The free energy calculation was performed for the complex according to the MM-GBSA method and the following equation. However, other methods are also used, including free energy perturbation as well as molecular mechanics Poisson-Boltzmann surface area (MMPBSA) [28]. The solvation model and force field in this process were considered VSGB 2.0 and OPLS3e, respectively.

$$
\Delta \mathrm{G}_{\text {bind }}=\mathrm{G}_{\text {complex }}-\left(\mathrm{G}_{\text {ligand }}+\mathrm{G}_{\text {receptor }}\right)
$$

\subsection{ADMET prediction.}

The pharmacokinetic properties of the alkaloid compounds were investigated using QikPrep software. Drug-like characteristics such as molecular weight (MW), H-bond donor, H-bond acceptor, central nervous system (CNS), $\log$ Po/w, polar surface area (PSA), PCaco, brain/blood partition coefficient $(\log \mathrm{BB})$, percentage of oral absorption, and metabolism, which are one of the most significant steps in drug discovery, were evaluated for hit compounds.

\subsection{Molecular dynamics simulation.}

Molecular dynamics simulation for top-scoring alkaloid compound complexed with COVID-19 E protein studied through Macro Model software from Schrödinger maestro suite (2020). The stochastic dynamics procedure was used because it includes random forces that simulate the buffering of a system by solvent molecules. Ligand energy in an aqueous solvent and extended cutoff was minimized using the OPLS3e force field. Polak-Ribier Conjugate Gradient (PRCG) method restarts every 3N iterations at a maximum iteration of 2500 and a convergence threshold of 0.05 for complex minimization. Eventually, simulation was provided using the stochastic dynamics procedure at a simulation temperature of $300 \mathrm{~K}$, a time step of $1.5 \mathrm{fs}$, and an equilibration time of $1 \mathrm{ps}$. Finally, $100 \mathrm{ps}$ was considered for simulation time.

\section{Results and Discussion}

The development of new antiviral drugs is a time-consuming process that requires complex clinical trials. Molecular docking is a new approach that requires less time and cost in screening millions of molecules. Also, it can be a powerful tool against disease [29]. The interactions and inhibitory effects of natural alkaloids on the coronavirus ion channel were studied by molecular docking. The molecular docking of 3,200 alkaloids resulted in the selection of 25 compounds (Figure 2), which all had a docking score of less than $-8.09 \mathrm{kcal} / \mathrm{mol}$. 
The free binding energy calculation and pharmacokinetic characteristics were employed to achieve these 25 alkaloid compounds. Psammaplysin U (NA-1) with the lowest docking score $(-13.26 \mathrm{kcal} / \mathrm{mol})$ and the lowest glide emodel $(-67.93 \mathrm{kcal} / \mathrm{mol})$ was determined to have the best interaction with the protein. The lowest free binding energy $\left(\Delta \mathrm{G}_{\mathrm{bind}}\right)$ of $-93.11 \mathrm{kcal} / \mathrm{mol}$ was obtained for the purpurealidin D compound as the most stable hit pose. The docking score, free binding energy, and natural alkaloids interactions with E protein are described in Table 1.

Table 1. Docking and free binding energy scores ( $\mathrm{kcal} / \mathrm{mol})$, with involved amino acids in interaction.

\begin{tabular}{|c|c|c|c|c|c|}
\hline No. & Molecule Name & $\begin{array}{l}\text { docking } \\
\text { score }\end{array}$ & $\begin{array}{l}\text { glide } \\
\text { emodel }\end{array}$ & $\Delta \mathbf{G}$ Bind & $\begin{array}{l}\text { Amino acid } \\
\text { Interaction }\end{array}$ \\
\hline NA-1 & Psammaplysin U & -13.258 & -93.673 & -87.757 & $\begin{array}{l}\text { Thr 30, Val 29, Val } \\
\text { 25, Leu } 28\end{array}$ \\
\hline NA-2 & Nocobactin NA & -11.322 & -78.634 & -85.722 & Arg 61 \\
\hline NA-3 & Purpurealidin D & -11.268 & -90.744 & -93.015 & Thr 30 \\
\hline NA-4 & Pyrinodemin A & -11.016 & -72.815 & -82.528 & Phe 26 \\
\hline NA-5 & Psammaplysin S & -10.788 & -84.019 & -77.567 & Arg 61, Thr 30 \\
\hline NA-6 & Araplysillin V & -10.522 & -69.969 & -60.201 & Thr 30 \\
\hline NA-7 & 19-hydroxypsammaplysin W & -9.848 & -72.915 & -76.823 & Leu 28 \\
\hline NA-8 & Psammaplysin V & -9.800 & -82.253 & -91.450 & Thr 30, Leu 28 \\
\hline NA-9 & 4-Phenylbutyl glucosinolate & -9.729 & -55.042 & -51.369 & $\begin{array}{l}\text { Ala 22, Leu 18, Asn } \\
15, \text { Phe } 26\end{array}$ \\
\hline NA-10 & N-desmethylthaxtomin C & -9.637 & -41.113 & -34.061 & Ala 22, Phe 23 \\
\hline NA-11 & Psammaplysin W & -9.534 & -77.171 & -82.854 & Thr 30, Phe 26 \\
\hline NA-12 & Montamine & -9.430 & -79.448 & -68.230 & Thr 30, Phe 26 \\
\hline NA-13 & Araplysillin IV & -9.374 & -70.125 & -64.808 & Thr 30 \\
\hline NA-14 & Gluconasturtiin & -9.080 & -48.692 & -47.454 & $\begin{array}{l}\text { Ile 46, Arg 61, Phe } \\
26\end{array}$ \\
\hline NA-15 & 19-hydroxypsammaplysin T & -8.882 & -79.716 & -78.062 & Arg 61 \\
\hline NA-16 & $\begin{array}{l}\text { 2,4-Dinitrophenylhydrazone-1,7-Diphenyl-4,6- } \\
\text { heptadien-3-one }\end{array}$ & -8.770 & -58.193 & -66.666 & Phe 26 \\
\hline NA-17 & Antibiotic L 654040 & -8.641 & -65.389 & -44.457 & $\begin{array}{l}\text { Phe 26, Leu18, } \\
\text { Asn15 }\end{array}$ \\
\hline NA-18 & Dehydroascorbic acid-2,3-Bisphenylhydrazone & -8.569 & -44.134 & -53.469 & Thr 30, Phe 26 \\
\hline NA-19 & Psammaplysin P & -8.506 & -84.687 & -89.222 & Thr 30, Arg 61 \\
\hline NA-20 & $\begin{array}{l}\text { O1-[3-(methyl-[1,3,4]oxadiazol-2-yl)-phenyl]- } \\
\text { beta-D-glucopyranuronic acid }\end{array}$ & -8.419 & -50.621 & -54.133 & Ile 46, Asn 64 \\
\hline NA-21 & Pyrinodemin B & -8.415 & -68.287 & -75.003 & Phe 26 \\
\hline NA-22 & Araplysillin VI & -8.245 & -82.991 & -74.214 & Thr 30, Arg 61 \\
\hline NA-23 & $\begin{array}{l}\text { 7-Chlor-2-ethylamino-5-phenyl-3H-1,3,4- } \\
\text { benzotriazepin }\end{array}$ & -8.148 & -39.451 & -46.747 & Phe 26, Phe 23 \\
\hline NA-24 & Aurachin A & -8.144 & -44.934 & -62.567 & Arg 61 \\
\hline NA-25 & 2-Amino-7-chlor-5-phenyl-1,3,4-benzotriazepin & -8.091 & -34.291 & -40.995 & Phe 26 , Phe 23 \\
\hline
\end{tabular}

\subsection{Interactions of top-scoring alkaloid compounds with pentameric ionic channel.}

The top six compounds with the highest docking score $(-13.258$ to $-10.522 \mathrm{kcal} / \mathrm{mol})$ are psammaplysin U, nocobactin NA, purpurealidin D, Pyrinodemin A, Psammaplysin S, and Araplysillin V, respectively. 2D and 3D interactions between the pentameric ion channel and the hit poses are shown in Figures 3-8. Compound NA-1, which has halogen and H-bond interactions with Thr 30, Val 29, Val 25, and Leu 28 amino acids, possesses the highest binding affinity of $-13.258 \mathrm{kcal} / \mathrm{mol}$ with E protein pentameric ion channel (5X29). Furthermore, the free binding energy of $-87.75 \mathrm{kcal} / \mathrm{mol}$ of psammaplysin $U$ indicates the stability of the compound at the binding site. Carbonyl oxygen with Thr 30 amino acid in the chain A, the nitrogen atoms of the amide with Val 25, and hydroxyl with Val 29 in chain B form a hydrogen bond, while Leu 28 in B chain form a halogen bond with the bromine of benzene ring (Figure 3). Biological activities such as antimalarial, anti-HIV, antifouling, and cytotoxic activity were demonstrated by psammaplysin derivatives extracted from nine different species of Verongida sponge [30-32]. The NA-1 compound contains an isobranch monoenoeic fatty acid with the 
molecular formula of $\mathrm{C}_{38} \mathrm{H}_{53} \mathrm{Br}_{4} \mathrm{~N}_{3} \mathrm{O}_{7}$, which can be extracted from the Balinese marine sponge (Aplysinella strongylata). Nocobactin NA (NA-2) interacts with the amino acid of Arg 61 in the E chain. The hydroxyl and the oxygen atom of the carbonyl group of NA-2 establish hydrogen bonds with the amino acid simultaneously.
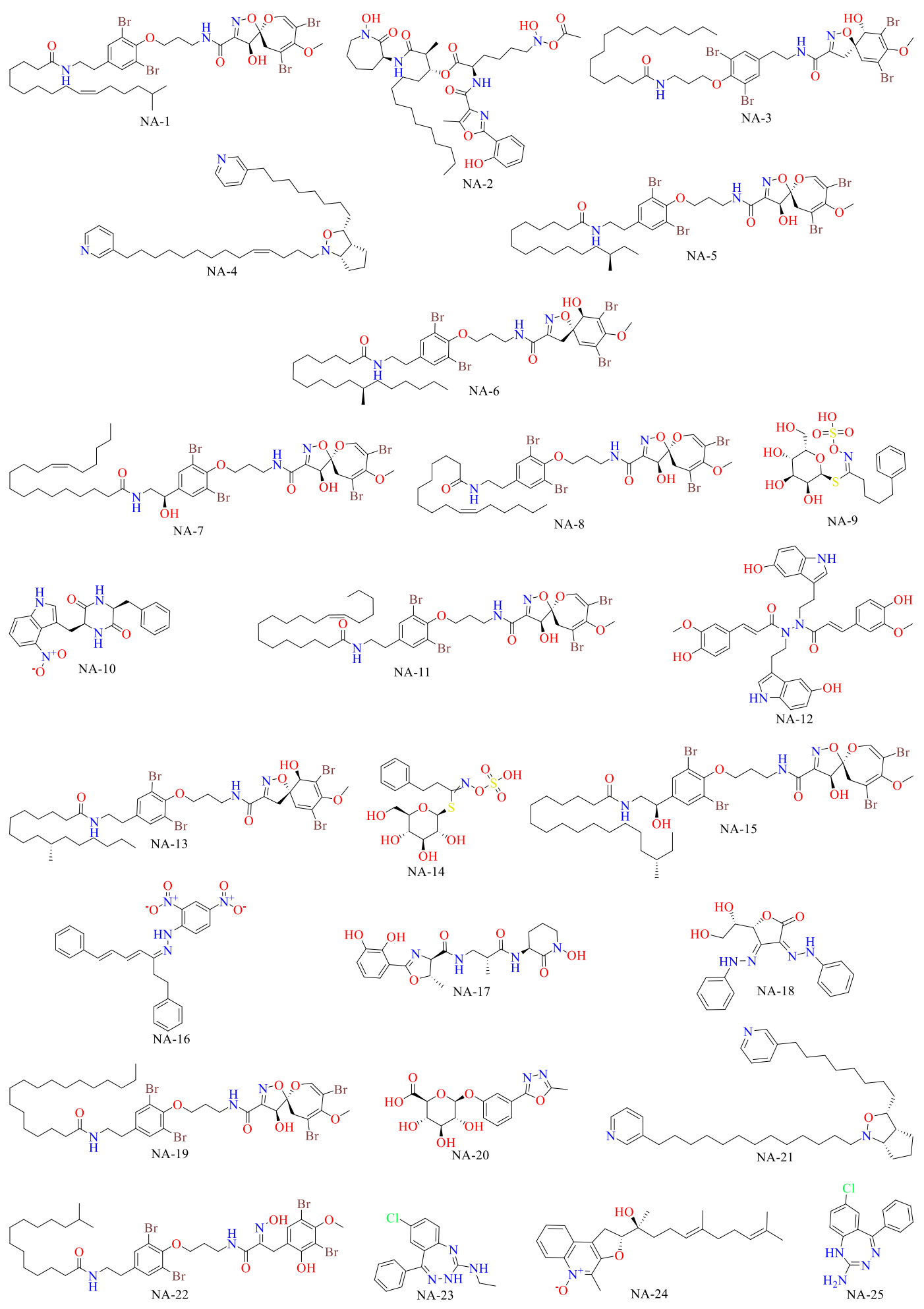

Figure 2. The $2 \mathrm{D}$ chemical structure of top-scoring alkaloids.

Also, a docking score of $-11.32 \mathrm{kcal} / \mathrm{mol}$ and free binding energy of $-85.72 \mathrm{kcal} / \mathrm{mol}$ was calculated for the compound (Figure 4). Nocobactin NA is produced by Nocardia asteroid and Nocardia farcinica, which usually grow before iron. NA-2 is a lipid-soluble compound 
whose tumor-specific cytotoxicity properties were shown by Sakagami et al. (2005) [33]. The oxygen of the carboxyl and carbonyl group in the compound of Purpurealidin D leads to a binding affinity of $-11.28 \mathrm{kcal} / \mathrm{mol}$ by forming hydrogen bonds with the amino acid of $\mathrm{Thr} 30$ in chain A. The desired compound with a free energy of $-93.01 \mathrm{kcal} / \mathrm{mol}$ in the pentameric ion channel was selected as the third effective compound in this study (Figure 5). The purpurealidin D is a compound of Bromotyrosine alkaloids found in sponge Psammaplysilla purpurea [34].

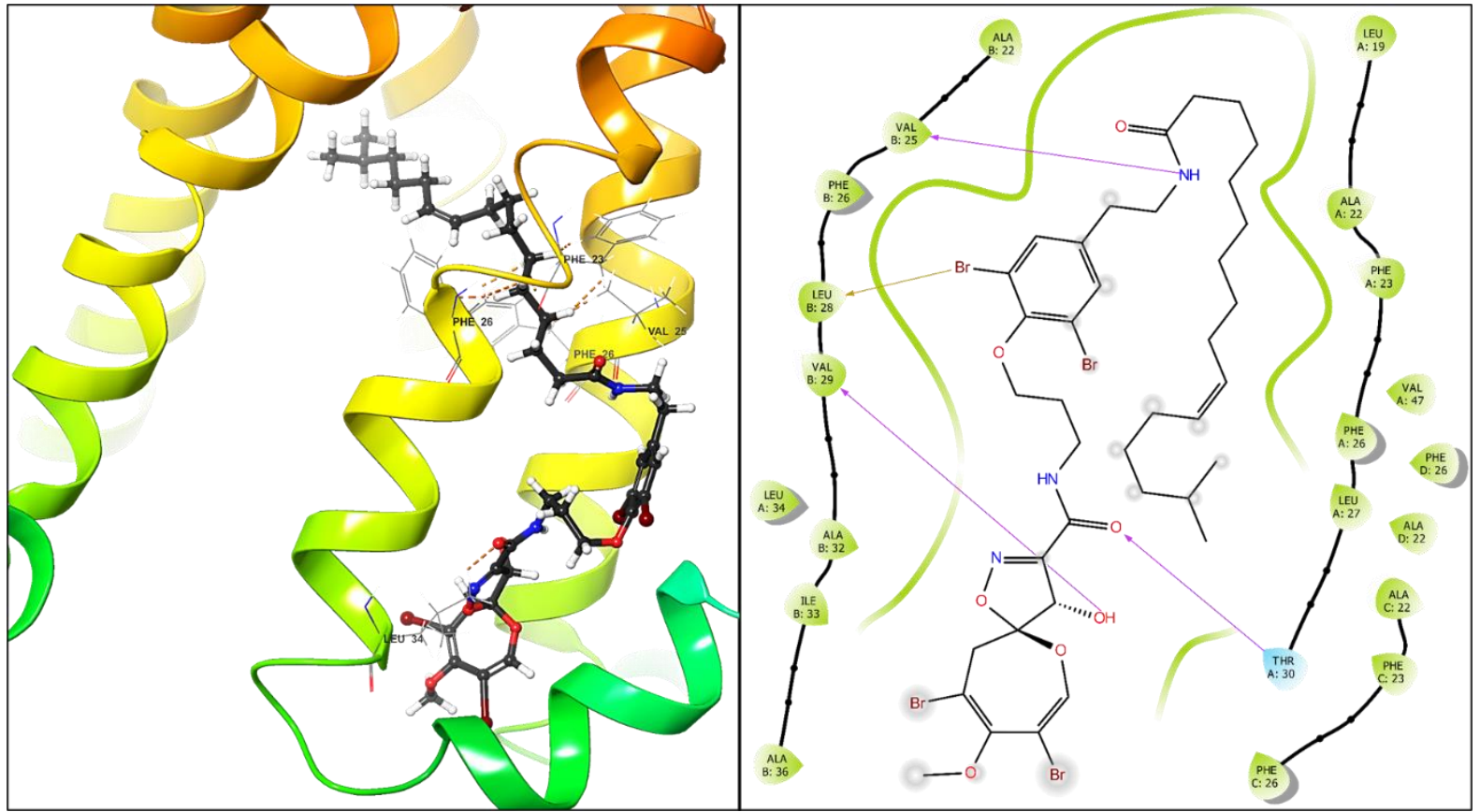

Figure 3. The $2 \mathrm{D}$ and $3 \mathrm{D}$ interaction of the pentameric ion channel - Psammaplysin U complex. The 2D map shows the importance of the involved amino acid in the binding site.

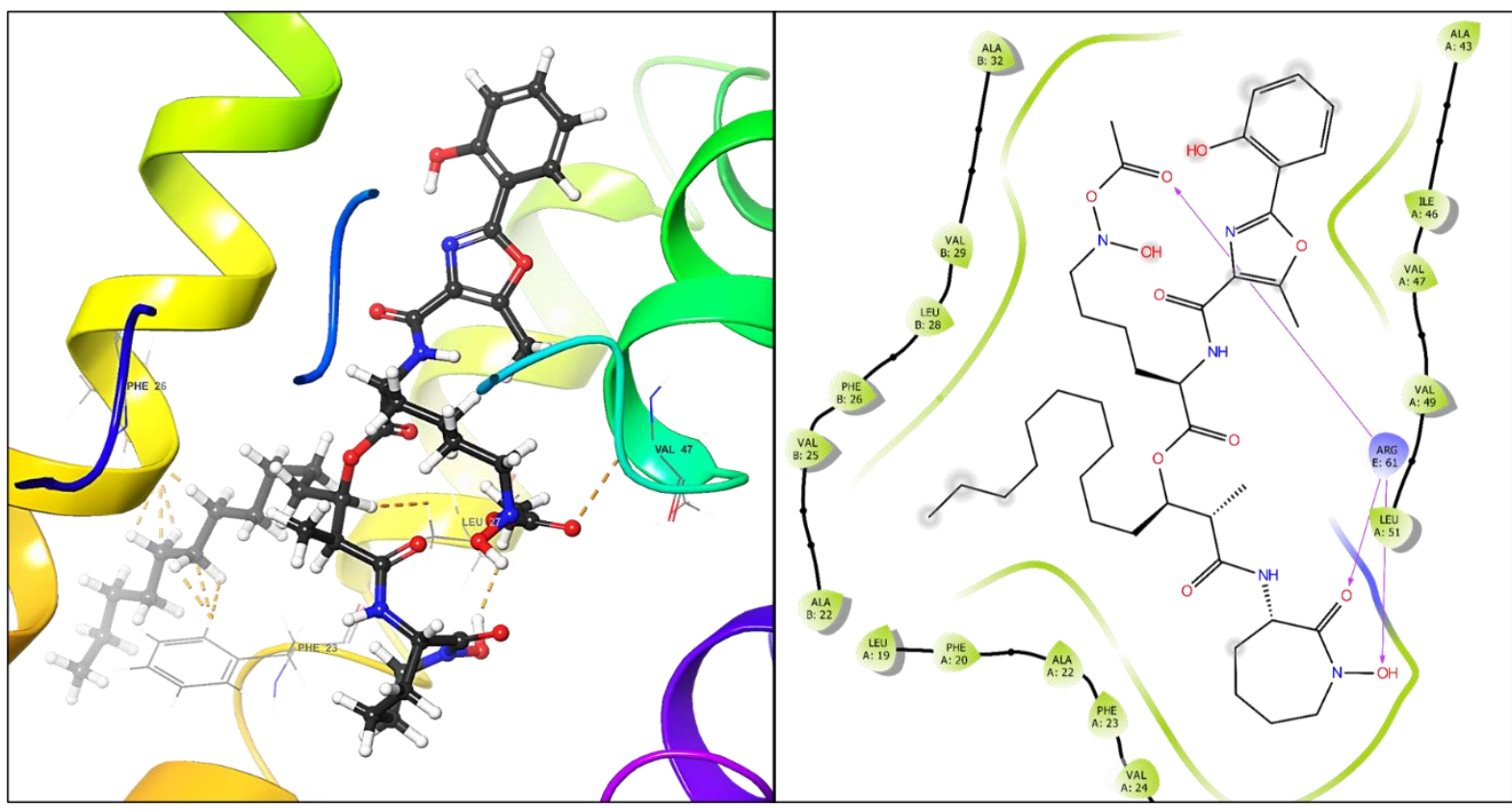

Figure 4. The 2D and 3D interaction of the pentameric ion channel - Nocobactin NA complex. The 2D map shows the importance of the involved amino acid in the binding site.

The free binding energy of Pyrinodemin A was calculated as $-82.53 \mathrm{kcal} / \mathrm{mol}$, and the docking score energy was estimated at $-11.02 \mathrm{kcal} / \mathrm{mol}$. In Figure 6 , it can be seen that the pyridine ring in the NA-4 compound induces a $\pi-\pi$ stacking with Phe 26 in the C chain, which blocks the ionic channel and disturbs the internal balance of the virus. Pyrinodemin A, with the 
molecular formula of $\mathrm{C}_{38} \mathrm{H}_{59} \mathrm{~N}_{3} \mathrm{O}$, is a cytotoxic pyridine alkaloid found in Kinawan marine sponge (Amphimedon sp.). Tesuda et al. (1999) [35] reported that the NA-4 compound had cytotoxic properties against murine leukemia with $\mathrm{IC}_{50}=0.058 \mu \mathrm{g} / \mathrm{ml}$.

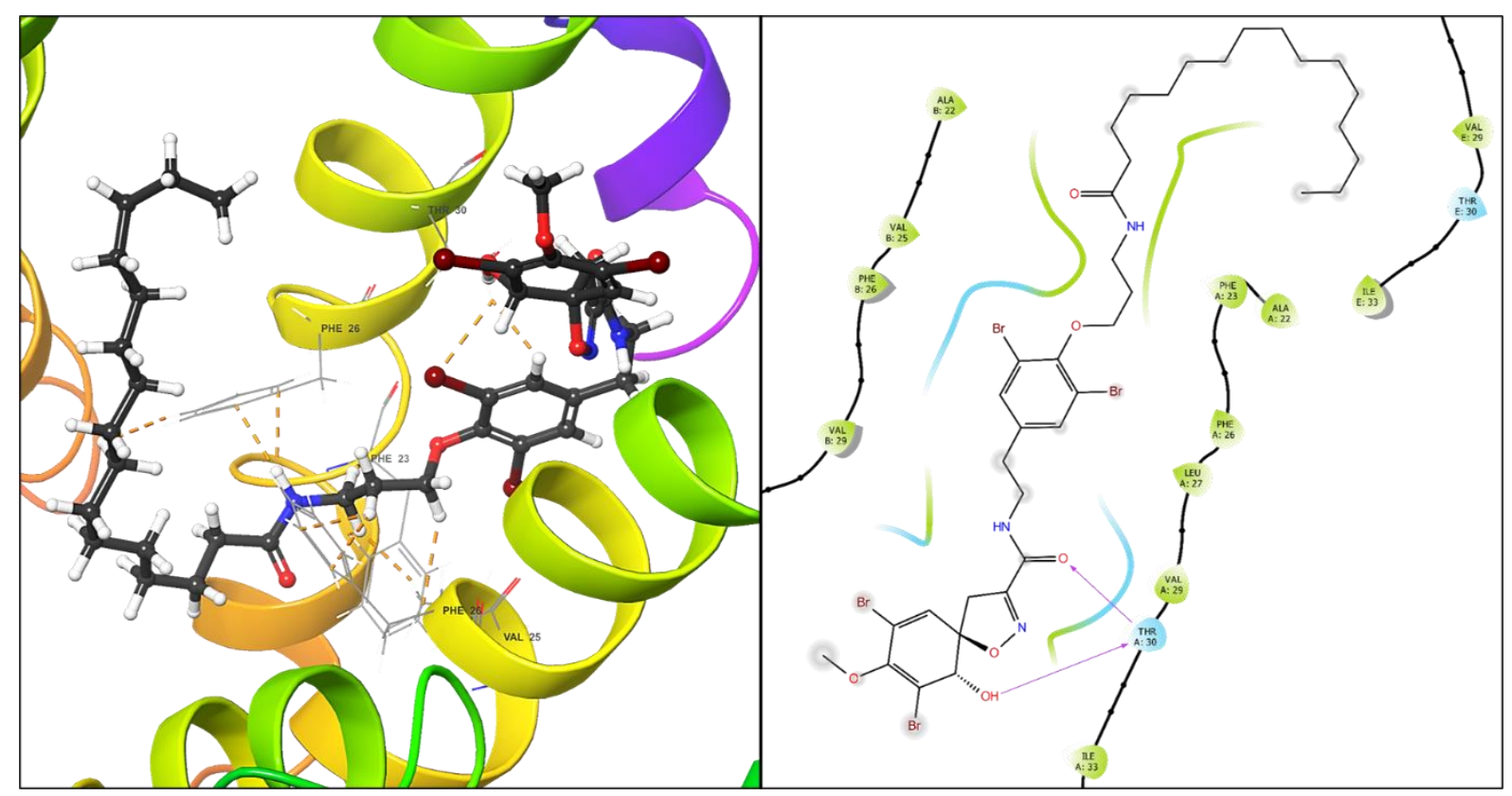

Figure 5. The 2D and 3D interaction of the pentameric ion channel - Purpurealidin D complex. The 2D map shows the importance of the involved amino acid in the binding site.

This compound has antiviral characteristics due to isoxazolidine scaffolds. NA-5 compound (Psammaplysin S) exhibits docking energy of $-10.79 \mathrm{kcal} / \mathrm{mol}$ and free energy of $84.01 \mathrm{kcal} / \mathrm{mol}$ by forming hydrogen interactions with protein $\mathrm{E}$. The nitrogen of the isoxazole ring creates an H-bond with the amino acid of Arg 61 in chain D. Moreover, the Thr 30 in chain $\mathrm{E}$ forms a hydrogen bond with the amide group's nitrogen atom (Figure 7).

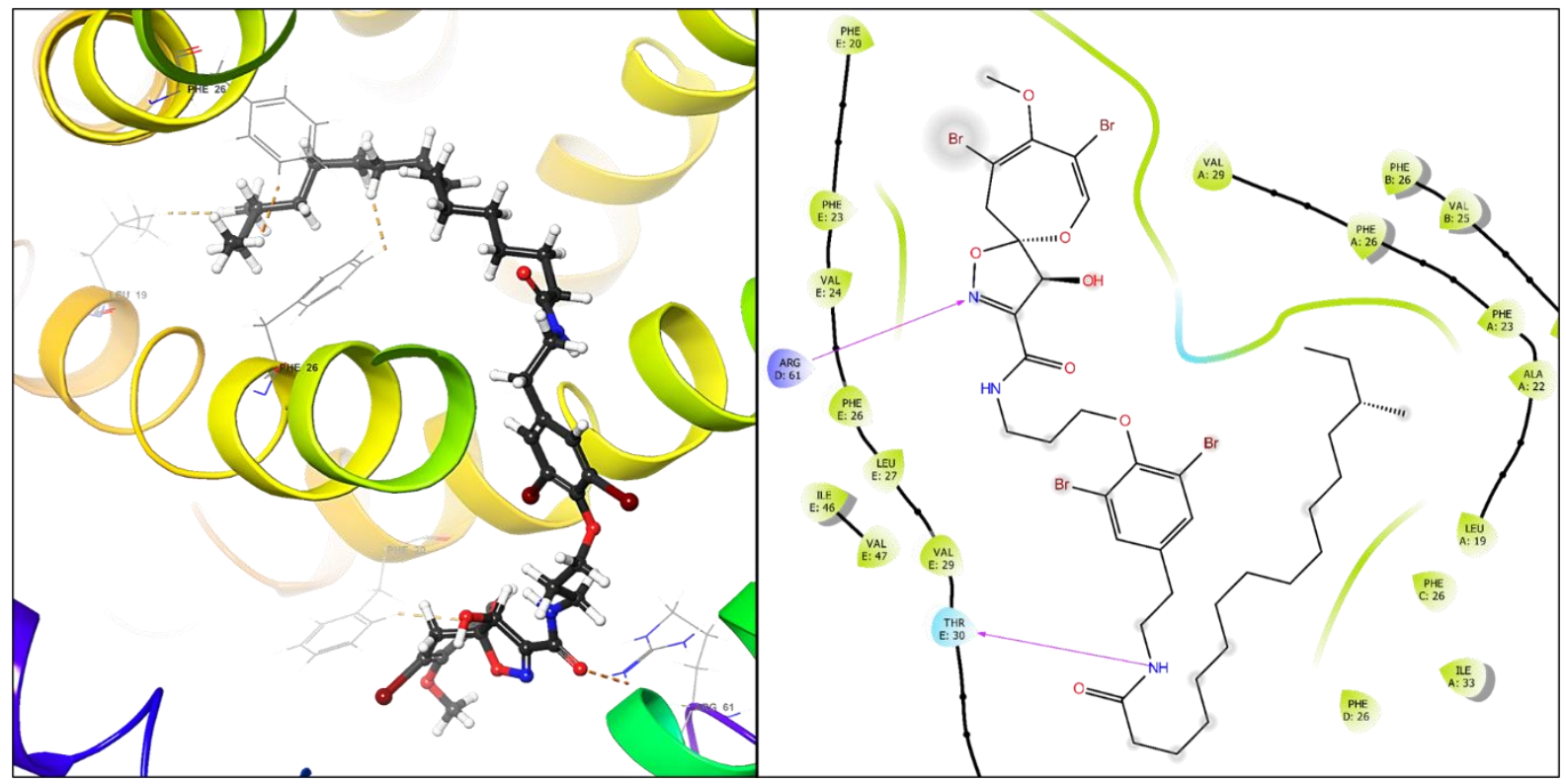

Figure 6. The 2D and 3D interaction of the pentameric ion channel - Pyrinodemin A complex. The 2D map shows the importance of the involved amino acid in the binding site.

Figure 8 shows the hydrogen bond interaction of the Araplysillin V (NA-6) compound with Thr 30 in the A chain, resulting in a binding affinity of $-10.53 \mathrm{kcal} / \mathrm{mol}$ and free energy 
of $-60.20 \mathrm{kcal} / \mathrm{mol}$. Suberea ianthelliformis sponge contains Araplysillin V, which has an antiplasmodial effect with $\mathrm{IC}_{50}=50.5 \mu \mathrm{M}$ [36].

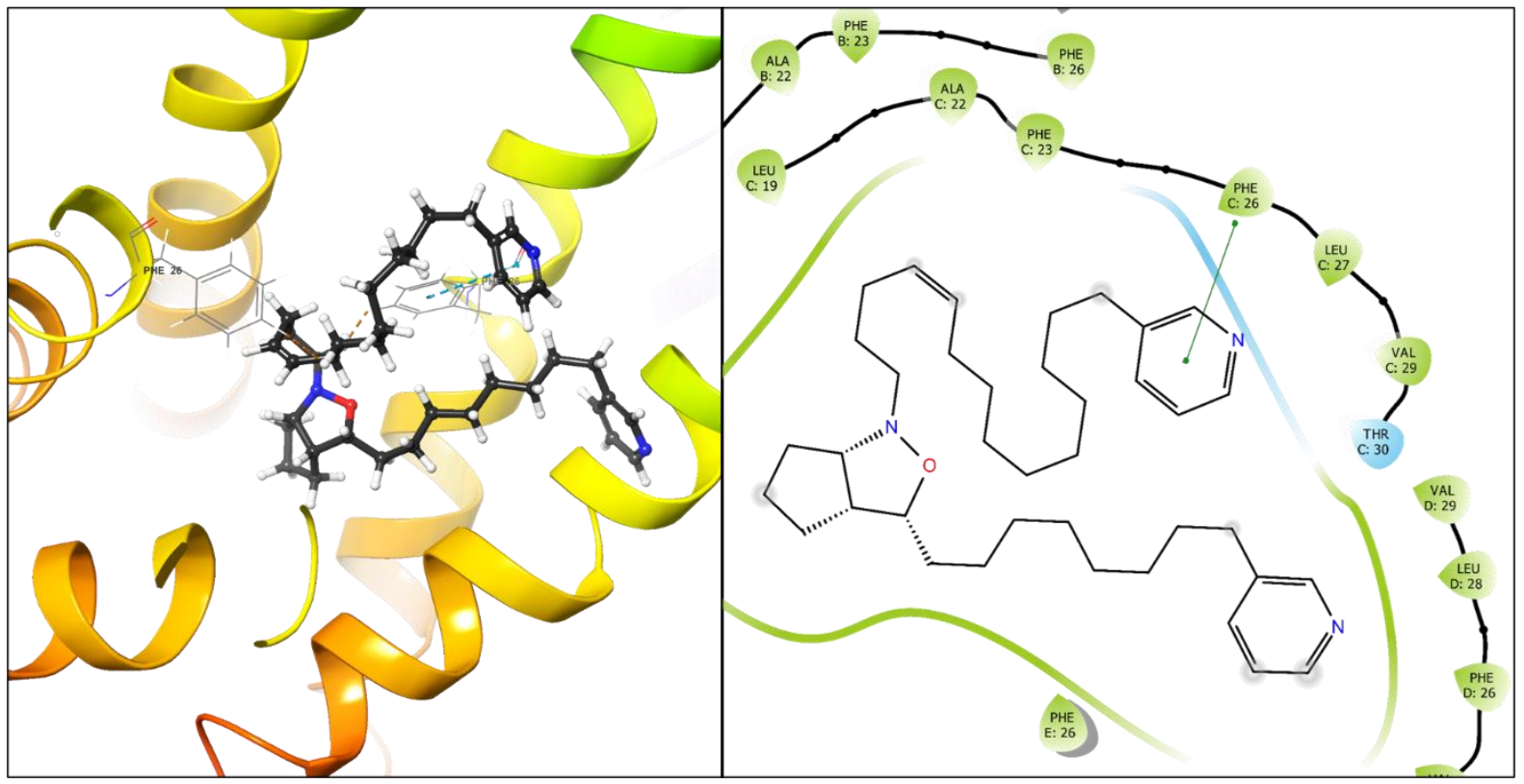

Figure 7. The 2D and 3D interaction of the pentameric ion channel - Psammaplysin S complex. The 2D map shows the importance of the involved amino acid in the binding site.

\subsection{ADMET prediction.}

Drug-likeness properties for alkaloid compounds were calculated by the QikProp panel and filtered the compounds to the 25 final hit poses. Lipinski's rule of 5 (molecular weight, octanol-water partition coefficient, hydrogen acceptor and donor), toxicity-related descriptors (PCaco, $\log \mathrm{BB}$, percentage of oral absorption, and CNS activity), and several parameters, including metabolism and PSA (Veber rule), were predicted. According to the results in Table 2 , these natural alkaloid compounds proved agreeable in silico pharmacokinetic properties. One of the most prominent features of the drug is absorption, which makes it easy to use.

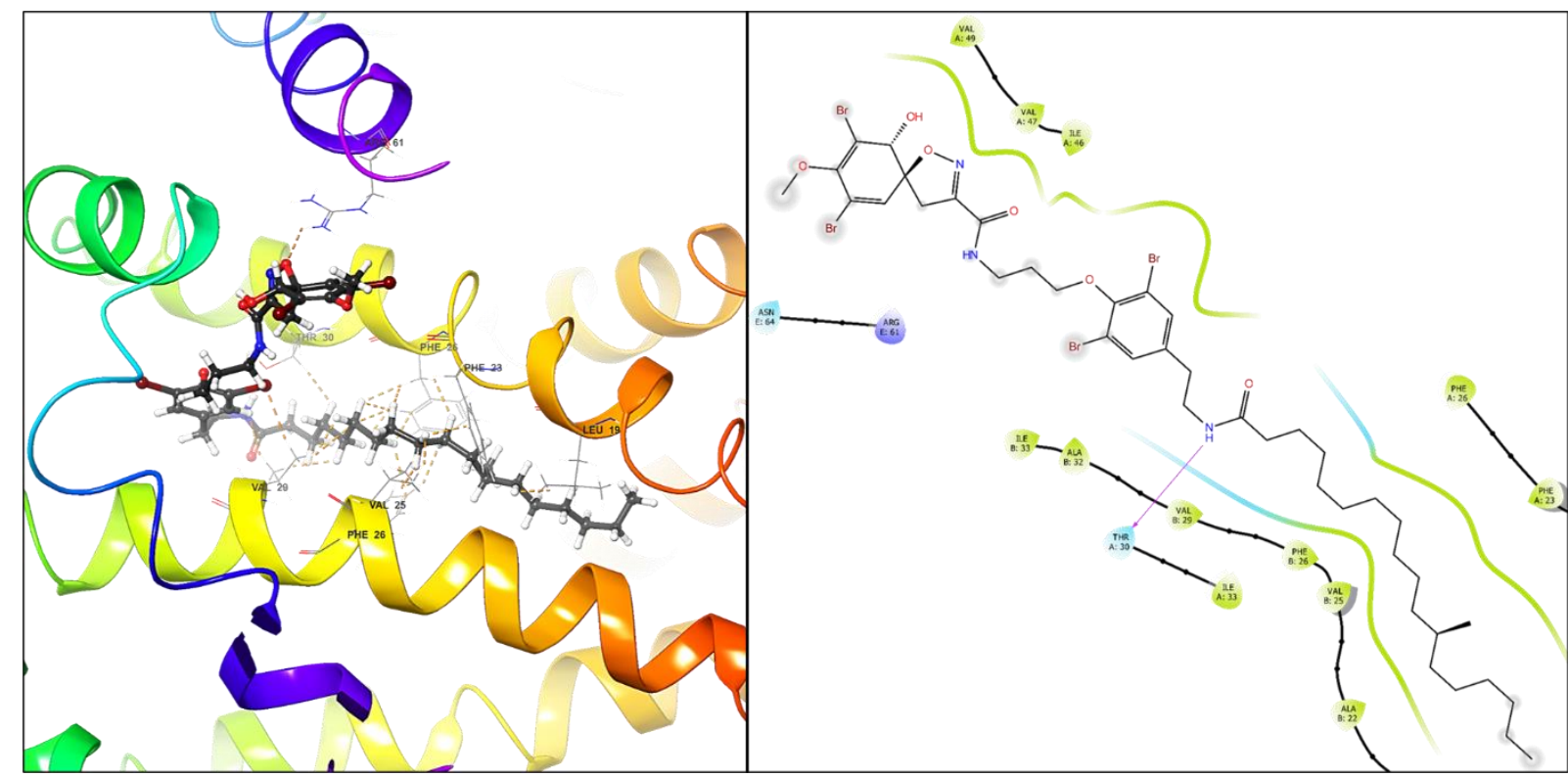

Figure 8. The 2D and 3D interaction of the pentameric ion channel - Araplysillin V complex. The 2D map shows the importance of the involved amino acid in the binding site. 
The factor of $\log \mathrm{P}$ indicates the hydrophilicity of the drug, which the high value of the $\log \mathrm{P}$ leads to a decrease in drug absorption. All hit alkaloids except compounds of NA-9, NA12, NA-14, NA-17, and NA-20 had an oral absorption of more than 50\%. Among the top 6 selected compounds, NA-1, NA-4, NA-5, and NA-6 showed $100 \%$ oral absorption, and NA-3 compounds noted more than $95 \%$ absorption. CNS activity of the entire 25 compounds except for NA-4, NA-23, NA-24, and NA-25 were reported -2. However, the compounds mentioned were in an acceptable range with no penetration into the central nervous system. Besides, hydrogen acceptors and donors displayed great results for all 25 alkaloids. Additional information on ADMET properties is presented in Table 2.

Table 2. Pharmacokinetic properties of natural alkaloids.

\begin{tabular}{c|c|c|c|c|c|c|c|c|c|c} 
No. & MW & PSA & H-Do & H-Ac & CNS & $\begin{array}{c}\text { Absorption } \\
(\boldsymbol{\%})\end{array}$ & PCaco & Log BB & Log P & Metab \\
\hline NA-1 & 983.469 & 135.784 & 2 & 9.7 & -2 & 100 & 344.159 & -2.259 & 9.923 & 7 \\
\hline NA-2 & 787.949 & 245.202 & 2.5 & 14.95 & -2 & 52.587 & 37.675 & -4.539 & 6.201 & 6 \\
\hline NA-3 & 955.458 & 133.900 & 3 & 9.95 & -2 & 95.317 & 148.431 & -2.983 & 9.465 & 6 \\
\hline NA-4 & 573.904 & 36.087 & 0 & 6.2 & -2 & 100 & 735.423 & -1.053 & 8.996 & 8 \\
\hline NA-5 & 985.484 & 139.250 & 2 & 9.7 & -2 & 100 & 258.206 & -2.629 & 10.177 & 5 \\
\hline NA-6 & 997.539 & 134.553 & 3 & 9.95 & -2 & 100 & 151.544 & -3.040 & 10.147 & 6 \\
\hline NA-7 & 1027.522 & 155.531 & 3 & 11.4 & -2 & 86.212 & 184.076 & -3.180 & 9.838 & 7 \\
\hline NA-8 & 969.442 & 143.883 & 2 & 9.7 & -2 & 100 & 179.631 & -2.711 & 9.750 & 7 \\
\hline NA-9 & 451.506 & 186.037 & 5 & 14 & -2 & 33.827 & 2.407 & -3.639 & 0.009 & 7 \\
\hline NA-10 & 378.387 & 134.819 & 3 & 6 & -2 & 57.631 & 21.631 & -1.986 & 1.160 & 5 \\
\hline NA-11 & 1011.522 & 139.583 & 2 & 9.7 & -2 & 100 & 233.745 & -2.705 & 10.365 & 7 \\
\hline NA-12 & 702.762 & 179.344 & 6 & 9.5 & -2 & 26.561 & 11.254 & -4.447 & 5.573 & 8 \\
\hline NA-13 & 969.485 & 131.902 & 3 & 9.95 & -2 & 100 & 200.475 & -2.761 & 9.819 & 6 \\
\hline NA-14 & 423.452 & 173.035 & 5 & 14 & -2 & 39.845 & 6.672 & -2.890 & -0.317 & 7 \\
\hline NA-15 & 1029.537 & 160.514 & 3 & 11.4 & -2 & 83.444 & 114.779 & -3.581 & 9.992 & 5 \\
\hline NA-16 & 442.473 & 108.481 & 1 & 4 & -2 & 88.788 & 172.307 & -2.390 & 5.939 & 5 \\
\hline NA-17 & 434.448 & 179.740 & 3.25 & 11.45 & -2 & 36.794 & 21.226 & -2.607 & -0.161 & 5 \\
\hline NA-18 & 354.365 & 121.243 & 3 & 9.4 & -2 & 81.276 & 318.413 & -1.689 & 1.628 & 7 \\
\hline NA-19 & 999.511 & 132.931 & 2 & 9.7 & -2 & 100 & 383.693 & -2.585 & 10.518 & 5 \\
\hline NA-20 & 352.300 & 168.502 & 3 & 11.05 & -2 & 39.395 & 5.366 & -2.588 & -0.104 & 6 \\
\hline NA-21 & 561.893 & 41.365 & 0 & 6.2 & 0 & 100 & 907.398 & -0.978 & 9.096 & 6 \\
\hline NA-22 & 941.431 & 141.081 & 3 & 8.95 & -2 & 95.255 & 132.032 & -3.136 & 9.610 & 6 \\
\hline NA-23 & 298.774 & 62.154 & 2 & 3.5 & 1 & 100 & 2230.237 & 0.010 & 3.821 & 0 \\
\hline NA-24 & 395.541 & 46.688 & 1 & 2.5 & 0 & 100 & 2860.122 & -0.546 & 6.888 & 10 \\
\hline NA-25 & 270.721 & 78.453 & 3 & 3.5 & -1 & 89.643 & 531.048 & -0.483 & 2.378 & 0
\end{tabular}

MW = Molecular weight $(\mathrm{g} / \mathrm{mol}) ; \mathrm{PSA}=$ Polar surface area; H-Ac $=$ No. of hydrogen bond acceptors; H-Do =

No. of hydrogen bond donors; $\mathrm{CNS}=$ Central nervous system; Absorption $(\%)=$ Percentage of human oral absorption; $\mathrm{PCaco}=$ Predicted Caco-2 cell permeability; $\operatorname{LogBB}=$ brain/blood partition coefficient; $\operatorname{LogP}=$ Predicted octanol/water partition coefficient; Metab = Metabolism

\subsection{Molecular dynamics analysis.}

Molecular dynamics simulation was used to understand the bonds in the ligand-ion channel complex accurately. Molecular dynamics simulations were evaluated for a $100 \mathrm{ps}$ trajectory to achieve the top ligand's stability and mechanism of interaction with the pentameric ion channel in 150 frames. The system hit a stable equilibrium after about 60 picoseconds from the simulation process (Figure 9).

According to the standard, the convergence threshold was considered 0.05 , and if a difference of $0.05 \mathrm{~kJ} / \mathrm{mol}$ is observed between at least two calculated potential energies, the system will iteratively be optimized. The simulation's film shows that the first interaction of ligand-protein is the nitrogen atom of Psammaplysin U with the Val 25 in the B chain. Besides, in the equilibrium times, the most interactions were the halogen bond of the bromine with Thr 30 in chain A. 


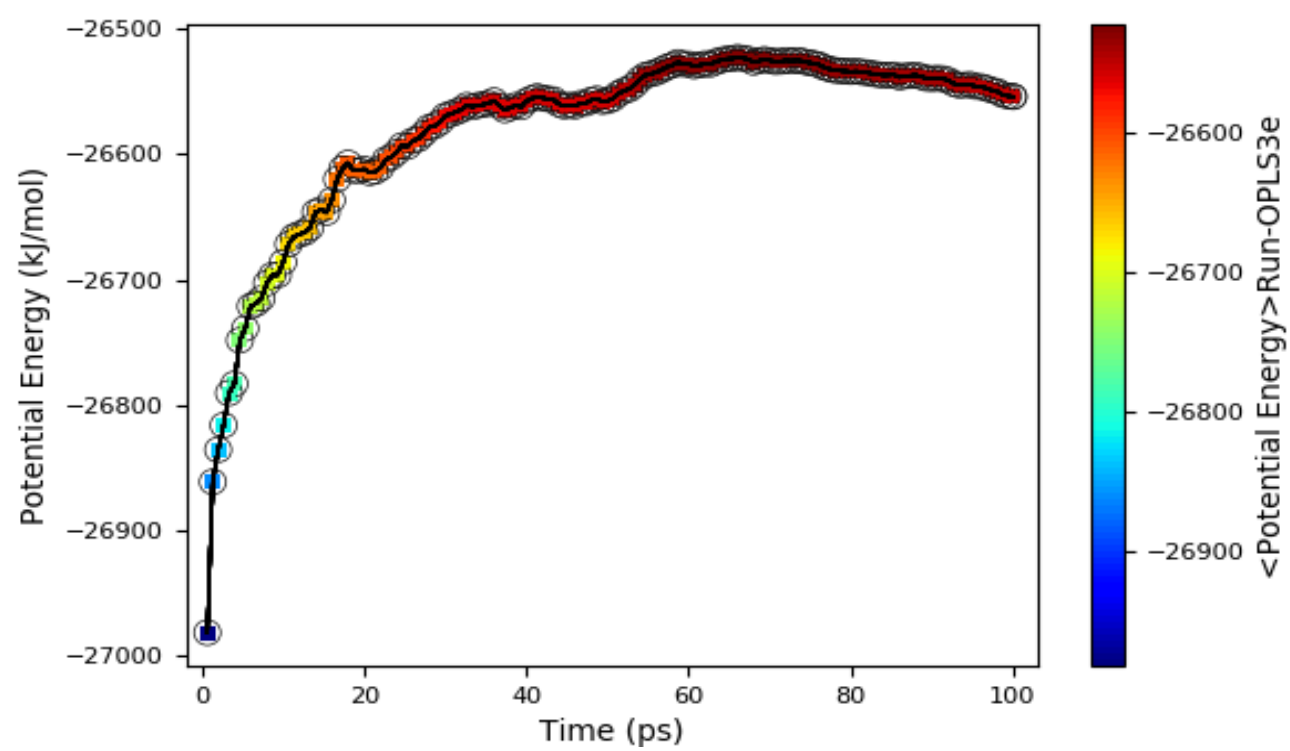

Figure 9. Convergence graph of the pentameric ion channel-Psammaplysin U complex in terms of potential energy.

\section{Conclusions}

The present study was performed to identify and determine an appropriate inhibitor of natural alkaloid compounds to block the ion channel of the coronavirus in the current situation with no definite medication. The compounds of NA-1 to NA-6 with the highest docking score were identified as hit poses by molecular docking study. Post-screening analyses such as free binding energy and pharmacokinetic characteristics have not been ineffective in selecting these compounds. So that among these compounds, the most stable compound in the presence of protein is NA-3 with $-93.01 \mathrm{kcal} / \mathrm{mol}$, and the unstable compound with the energy of -60.20 $\mathrm{kcal} / \mathrm{mol}$ was NA-6. Finally, the compound of Psammaplysin U with docking score of -13.26 $\mathrm{kcal} / \mathrm{mol}$, glide emodel of $-93.67 \mathrm{kcal} / \mathrm{mol}$, and hydrogen interactions with amino acids of Val 25, and Val 29 in the chain B, Thr 30 in chain A, also halogen interaction with Leu 28, was selected as the superior alkaloid compound. The first interaction in the molecular dynamics simulation was the hydrogen bond of the NA-1 compound with the amino acid of Val 25 in the $B$ chain of the virus's ion channel. Psammaplysin $U$ could be a suitable compound for equilibrium disruption of the virus and ultimately the disease therapy.

\section{Funding}

This research received no external funding.

\section{Acknowledgments}

The authors thank the Research Council of Shahid Beheshti University, Tehran, Iran, for their financial support.

\section{Conflicts of Interest}

The authors declare no conflict of interest. 


\section{References}

1. Harapan, H.; Itoh, N.; Yufika, A.; Winardi, W.; Keam, S.; Te, H.; Megawati, D.; Hayati, Z.; Wagner, A.L.; Mudatsir, M. Coronavirus disease 2019 (COVID-19): A literature review. Journal of infection and public health 2020, https://doi.org/10.1016/j.jiph.2020.03.019.

2. Marshall, M. COVID's toll on smell and taste: what scientists do and don't know. Nature 2021, https://doi.org/10.1038/d41586-021-00055-6.

3. Fehr, A.R.; Perlman, S. Coronaviruses: an overview of their replication and pathogenesis. Coronaviruses 2015, https://doi.org/10.1007/978-1-4939-2438-7_1.

4. Sumirtanurdin, R.; Barliana, M.I. Coronavirus disease 2019 vaccine development: an overview. Viral Immunology 2021, 34, 134-144, https://doi.org/10.1089/vim.2020.0119.

5. Neuman, B.W.; Adair, B.D.; Yoshioka, C.; Quispe, J.D.; Orca, G.; Kuhn, P.; Milligan, R.A.; Yeager, M.; Buchmeier, M.J. Supramolecular architecture of severe acute respiratory syndrome coronavirus revealed by electron cryomicroscopy. Journal of virology 2006, 80, 7918-7928, https://doi.org/10.1128/JVI.00645-06.

6. Lu, R.; Zhao, X.; Li, J.; Niu, P.; Yang, B.; Wu, H.; Wang, W.; Song, H.; Huang, B.; Zhu, N. Genomic characterisation and epidemiology of 2019 novel coronavirus: implications for virus origins and receptor binding. The lancet 2020, 395, 565-574, https://doi.org/10.1016/S0140-6736(20)30251-8.

7. Troyano-Hernáez, P.; Reinosa, R.; Holguín, Á. Evolution of SARS-CoV-2 Envelope, Membrane, Nucleocapsid, and Spike Structural Proteins from the Beginning of the Pandemic to September 2020: A Global and Regional Approach by Epidemiological Week. Viruses 2021, 13, 243, https://doi.org/10.3390/v13020243.

8. DeDiego, M.L.; Álvarez, E.; Almazán, F.; Rejas, M.T.; Lamirande, E.; Roberts, A.; Shieh, W.-J.; Zaki, S.R.; Subbarao, K.; Enjuanes, L. A severe acute respiratory syndrome coronavirus that lacks the E gene is attenuated in vitro and in vivo. Journal of virology 2007, 81, 1701-1713, https://doi.org/10.1128/JVI.0146706.

9. Godet, M.; L'Haridon, R.; Vautherot, J.-F.; Laude, H. TGEV corona virus ORF4 encodes a membrane protein that is incorporated into virions. Virology 1992, 188, 666-675, https://doi.org/10.1016/0042-6822(92)90521P.

10. Hasan, S.; Hossain, M.M. Analysis of COVID-19 M protein for possible clues regarding virion stability, longevity and spreading. 2020, https://doi.org/10.31219/osf.io/e7jkc.

11. Buzon, M.J.; Seiss, K.; Weiss, R.; Brass, A.L.; Rosenberg, E.S.; Pereyra, F.; Xu, G.Y.; Lichterfeld, M. Inhibition of HIV-1 integration in ex vivo-infected CD4 T cells from elite controllers. Journal of virology 2011, 85, 9646-9650, https://doi.org/10.1128/JVI.05327-11.

12. Jimenez-Guardeño, J.M.; Nieto-Torres, J.L.; DeDiego, M.L.; Regla-Nava, J.A.; Fernandez-Delgado, R.; Castaño-Rodriguez, C.; Enjuanes, L. The PDZ-binding motif of severe acute respiratory syndrome coronavirus envelope protein is a determinant of viral pathogenesis. PLoS Pathog 2014, 10, e1004320, https://doi.org/10.1371/journal.ppat.1004320.

13. Madan, V.; Castelló, A.; Carrasco, L. Viroporins from RNA viruses induce caspase-dependent apoptosis. Cellular microbiology 2008, 10, 437-451, https://doi.org/10.1111/j.1462-5822.2007.01057.x.

14. Fallah, M.S.; Bayati, M.; Najafi, A.; Behmard, E.; Javad, S. Molecular Docking Investigation of Antiviral Herbal Compounds as Potential Inhibitors of SARS-CoV-2 Spike Receptor. Biointerface Res. Appl. Chem 2021, 11, 12916-12924, https://doi.org/10.33263/BRIAC115.1291612924.

15. Mukherjee, A.K.; Basu, S.; Sarkar, N.; Ghosh, A.C. Advances in cancer therapy with plant based natural products. Current medicinal chemistry 2001, 8, 1467-1486, https://doi.org/10.2174/0929867013372094.

16. Özçelik, B.; Kartal, M.; Orhan, I. Cytotoxicity, antiviral and antimicrobial activities of alkaloids, flavonoids, and phenolic acids. Pharmaceutical biology 2011, 49, 396-402, https://doi.org/10.3109/13880209.2010.519390.

17. Suna, H.; Aoki, S.; Setiawan, A.; Kobayashi, M. Crambescidin 800, a pentacyclic guanidine alkaloid, protects a mouse hippocampal cell line against glutamate-induced oxidative stress. Journal of Natural Medicines 2007, 61, 288-295, https://doi.org/10.1007/s11418-007-0148-5.

18. Tempone, A.G.; Pieper, P.; Borborema, S.E.; Thevenard, F.; Lago, J.H.G.; Croft, S.L.; Anderson, E.A. Marine alkaloids as bioactive agents against protozoal neglected tropical diseases and malaria. Natural Product Reports 2021, https://doi.org/10.1039/D0NP00078G.

19. Shubina, L.K.; Makarieva, T.N.; von Amsberg, G.; Denisenko, V.A.; Popov, R.S.; Dyshlovoy, S.A. Monanchoxymycalin $\mathrm{C}$ with anticancer properties, new analogue of crambescidin 800 from the marine sponge Monanchora pulchra. Natural product research 2019, 33, 1415-1422, https://doi.org/10.1089/vim.2020.0119.

20. Youssef, F.S.; Alshammari, E.; Ashour, M.L. Bioactive alkaloids from genus Aspergillus: mechanistic interpretation of their antimicrobial and potential SARS-CoV-2 inhibitory activity using molecular modelling. International Journal of Molecular Sciences 2021, 22, 1866, https://doi.org/10.3390/ijms22041866. 
21. Omrani, M.; Bayati, M.; Mehrbod, P.; Asmari Bardazard, K.; Nejad-Ebrahimi, S. Natural products as inhibitors of COVID-19 main protease-A virtual screening by molecular docking. Pharm Sci https://doi.org/10.34172/ps.2021.11.

22. El-Demerdash, A.; Metwaly, A.M.; Hassan, A.; El-Aziz, A.; Mohamed, T.; Elkaeed, E.B.; Eissa, I.H.; Arafa, R.K.; Stockand, J.D. Comprehensive virtual screening of the antiviral potentialities of marine polycyclic guanidine alkaloids against SARS-CoV-2 (COVID-19). Biomolecules 2021, 11, 460, https://doi.org/10.3390/biom11030460.

23. Ismail, E.M.; Shantier, S.W.; Mohammed, M.S.; Musa, H.H.; Osman, W.; Mothana, R.A. Quinoline and quinazoline alkaloids against COVID-19: an in silico multitarget approach. Journal of Chemistry 2021, 2021, https://doi.org/10.1155/2021/3613268.

24. Papaneri, A.B.; Johnson, R.F.; Wada, J.; Bollinger, L.; Jahrling, P.B.; Kuhn, J.H. Middle East respiratory syndrome: obstacles and prospects for vaccine development. Expert review of vaccines 2015, 14, 949-962, https://doi.org/10.1586/14760584.2015.1036033.

25. Thariny, E.; Girija, A.S.; Brundha, M. Challenges in the synthesis of n-CoV vaccine-A review. Annals of the Romanian Society for Cell Biology 2021, 1035-1051.

26. Murphy, B.R.; Alling, D.; Snyder, M.; Walsh, E.; Prince, G.; Chanock, R.; Hemming, V.; Rodriguez, W.; Kim, H.; Graham, B. Effect of age and preexisting antibody on serum antibody response of infants and children to the $\mathrm{F}$ and $\mathrm{G}$ glycoproteins during respiratory syncytial virus infection. Journal of clinical microbiology 1986, 24, 894-898, https://doi.org/10.1128/jcm.24.5.894-898.1986.

27. Abreu, G.A.; Aguilar, M.H.; Covarrubias, D.H.; Durán, F.R. Amantadine as a drug to mitigate the effects of COVID-19. Med Hypotheses 2020, 140, 109755, https://doi.org/10.1016/j.mehy.2020.109755.

28. Ghosh, R.; Chakraborty, A.; Biswas, A.; Chowdhuri, S. Identification of alkaloids from Justicia adhatoda as potent SARS CoV-2 main protease inhibitors: An in silico perspective. Journal of Molecular Structure 2021, 1229, https://doi.org/10.1016/j.molstruc.2020.129489.

29. Meng, X.; Zhang, H.-X.; Mezei, M.; Cui, M. Molecular docking: a powerful approach for structure-based drug discovery. Curr comput-aid drug 7 (2). 2011, 146-157, https://doi.org/10.2174/157340911795677602.

30. Copp, B.R.; Ireland, C.M.; Barrows, L.R. Psammaplysin C: a new cytotoxic dibromotyrosine-derived metabolite from the marine sponge Druinella (= Psammaplysilla) purpurea. Journal of natural products 1992, 55, 822-823, https://doi.org/10.1021/np50084a021.

31. Tsukamoto, S.; Kato, H.; Hirota, H.; Fusetani, N. Ceratinamides A and B: New antifouling dibromotyrosine derivatives from the marine sponge Pseudoceratina purpurea. Tetrahedron 1996, 52, 8181-8186, https://doi.org/10.1016/0040-4020(96)00387-0.

32. Xu, M.; Andrews, K.T.; Birrell, G.W.; Tran, T.L.; Camp, D.; Davis, R.A.; Quinn, R.J. Psammaplysin H, a new antimalarial bromotyrosine alkaloid from a marine sponge of the genus Pseudoceratina. Bioorganic \& medicinal chemistry letters 2011, 21, 846-848, https://doi.org/10.1016/j.bmcl.2010.11.081.

33. Sakagami, H.; Ishihara, M.; Hoshino, Y.; Ishikawa, J.; Mikami, Y.; Fukai, T. Cytotoxicity of nocobactins NA-a, NA-b and their ferric complexes assessed by semiempirical molecular orbital method. in vivo 2005 , $19,277-282$.

34. Tilvi, S.; Rodrigues, C.; Naik, C.; Parameswaran, P.; Wahidhulla, S. New bromotyrosine alkaloids from the marine sponge Psammaplysilla purpurea. Tetrahedron 2004, 60, 10207-10215, https://doi.org/10.1016/j.tet.2004.09.009.

35. Tsuda, M.; Hirano, K.; Kubota, T.; Kobayashi, J.i. Pyrinodemin A, a cytotoxic pyridine alkaloid with an isoxazolidine moiety from sponge Amphimedon sp. Tetrahedron letters 1999, 40, 4819-4820, https://doi.org/10.1016/S0040-4039(99)00852-7.

36. Mani, L.; Jullian, V.; Mourkazel, B.; Valentin, A.; Dubois, J.; Cresteil, T.; Folcher, E.; Hooper, J.N.; Erpenbeck, D.; Aalbersberg, W. New antiplasmodial bromotyrosine derivatives from Suberea ianthelliformis Lendenfeld, 1888. Chemistry \& biodiversity 2012, 9, 1436-1451, https://doi.org/10.1002/cbdv.201100309. 